Université กn
de Montréal

Serge Sultan, Université de Montréal

How to cite this article:

Avoine-Blondin, J., Parent, V., Lahaye, M., Humbert, N., Duval, M., \& Sultan, S. (2017). Identifying domains of quality of life in children with cancer undergoing palliative care: A qualitative study with professionals. Palliative \& Supportive Care, 15(5), 565-574. https://doi.org/10.1017/S1478951516001048

DOI: $\quad$ https://doi.org/10.1017/S1478951516001048

PMID: $\quad 28137343$ 


\section{Identifying Domains of Quality of Life of Children with Cancer in Palliative Care: \\ A Qualitative Study with Professionals}

Josianne Avoine-Blondin ${ }^{12}$, Véronique Parent ${ }^{2}$, Magali Lahaye ${ }^{3}$, Nago Humbert ${ }^{14}$, Michel Duval $^{14}$, Serge Sultan ${ }^{14}$

1. CHU Sainte-Justine, Montréal, QC, Canada

2. Université de Sherbrooke, QC, Canada

3. Université Catholique de Louvain, Belgium

4. Université de Montréal, Montréal, QC, Canada

Corresponding author:

Serge Sultan

Department of Hematology/Oncology

CHU Sainte-Justine

3175, Chemin de la Côte-Sainte-Catherine

Montréal H3T 1C5

Québec, Canada

e-mail : serge.sultan@umontreal.ca

Tel. +1 (514) 343-6111 ext. 20727

Short title

Quality of Life Domains in Pediatric Palliative Care

Number of manuscript pages: 20

Number of figures: 1

Number of words without citations: 4642 


\section{Identifying Domains of Quality of Life of Children with Cancer in Palliative Care:}

\section{A Qualitative Study with Professionals}

Objective. The goal of pediatric palliative care (PC) is to maintain quality of life (QoL) of children whose life is threatened. However, there is little scientific data on the domains of QoL in this particular context and no measurement strategies are available. This study aims to describe the domains of QoL in the context of pediatric palliative care (PPC) in oncology, according to the professional caregivers' perception. Methods. Semi-structured interviews were conducted with a random sample of 20 professional caregivers from the Division of Hematology-Oncology at the CHU Sainte-Justine (Montréal, Canada). The caregivers were asked about their depiction of the QoL of children they have cared for in this context. Data were analyzed using inductive thematic content analysis. Results. The analysis allowed us to identify seven domains of QoL: Physical comfort; Alleviation of psychological suffering; Fun and the present moment; Sense of control; Feeling valued and appreciated; Feeling that life goes on; Meaningful social relationships.

Significance of Results. The caregivers' discourse recounts the regard that should be awarded to maintaining well-being, fun and the child's abilities based on the progression of the disease, and in maintaining his or her needs, especially social ones. The results also underline that all domains were positively referred to by professionals. Data from this study will lead to a better assessment of QoL according to the trajectory of a child with advanced cancer in PPC.

Key-words: Pediatric palliative care, Quality of life, Cancer, Professionals, Qualitative study 


\section{Introduction}

Recent advances have contributed to improving the curative care of children with cancer and increasing the survival rate for this population. However, no less than $20 \%$ of young individuals with cancer die each year (Advisory Committee of the Canadian Cancer Society, 2015). Pediatric palliative care (PPC) is about helping children and their families deal with their medical condition, while optimizing their quality of life (QoL). (Canadian Hospice Palliative Care Association, 2006; Government of Quebec, 2006; World Health Organization, 2013).

In order to describe and evaluate QoL in the specific context of PPC in oncology, various authors have collected the points of view of children with advanced cancer or that of their parents (Barrera et al., 2005; Friedrichsdorf et al., 2015; Hechler et al, 2006; Tomilinson et al., 2011; von Lützau et al., 2012). These studies depict a portrait of QoL that highlights the traditional dimensions of physical, emotional, and social QoL (Pépin, Carret, \& Sultan, 2015). Functional deficits in terms of mobility, sensation, and self-care, as well as pain and fatigue levels, were the main indicators used to evaluate the QoL of these young individuals (Tomilison et al., 2011). Research has also underlined more positive components of QoL such as maintaining the child's sense of normalcy, focusing on family activities, maintaining hope, and having fun or taking pleasure (Barrera et al., 2005; Friedrichsdorf et al., 2015; Hechler et al, 2006; Kamper et al., 2010; von Lützau et al., 2012).

Contrasting with these reports, available instruments to evaluate QoL in a pediatric context -and likely to be applied in PPC- remain focused on symptoms or functional deficits and are based on inappropriate time perspectives (e.g. one month) (Hinds et al., 2006; Liben, 2008). Importantly, no specific QoL instrument have been developed for the context of PPC as was evidenced by a recent systematic review (Coombes et al., 2016). As was stressed by the authors 
of this review, sensitivity is an essential quality in PPC but is typically not documented on available measures, probably because dimensions and time frames are not appropriate to evaluate change occurring in PPC. Widely used instruments in pediatrics such as the Pediatric Quality of Life Inventory (PedsQL) had inadequate validity when used in PPC suggesting that QoL structures between children with life-limiting illnesses and other populations may be different (Huang, Shenkman \& Madden, 2010). A recent research program has aimed to develop a tool to measure QoL in this context (PAC-QoL), but this is not based on domains generated by the participants or their caregivers and thus evaluates the same traditional domains (Cataudella et al., 2014; Morley et al., 2014). As the definition of QoL may be specific in PPC and the child's status may change drastically over short periods of time, there is a need for developing a new approach adapted to this context.

In summary, while the mission of PPC is to promote $\mathrm{QoL}$, the domains that $\mathrm{QoL}$ covers are still poorly defined. The traditional themes of QoL do not seem adequately specific for this population and are rather focused on deficits. Some studies have focused on the depiction of caregivers in this context, but more so on the definition of care quality criteria than on QoL (Andersen, Seecharan, \& Toce, 2004). Often, descriptions were made retrospectively -for instance by bereaved parents- and did not capture the very nature of the QoL "in the here and now". An increased awareness of the caregivers' representation of children's QoL would help complement the dimensions identified by previous studies and could lead to explicit definitions. Although it is not exempt of bias, professionals hold a unique view of children's status and wellbeing. Such clarification of the concept of QoL in this area is a necessary preliminary step before developing a sound measurement strategy. 
The objective of this study is to identify domains of QoL of children with cancer in palliative care according to the perceptions of professionals working in pediatric hematologyoncology. Our strategy is to help generate positive as well as negative images of QoL in order to operationalize what is meant by Quality of Life in this context. We wish to identify practical domains which could be defined precisely and be used for further outcome measurement developments.

\section{Methods}

This study is based on a qualitative research design calling for a descriptive inductive analysis (Braun \& Clarke, 2006; Lapierre, 1997). Based on a constructivist epistemological framework, this study aims to describe the concept of QoL from the perception of each individual, based on his or her experience as a caregiver who is currently caring for or who has cared for a child with advanced cancer.

It is of critical importance to mention our background and explicit our preconceptions to satisfy the scientific criterion of transparency. The authors of this report who have been particularly involved in data analysis are a doctoral student in psychology at the Centre of Psycho-Oncology at the CHU Sainte-Justine (JAB), and her doctoral supervisors at the Université de Montréal (SS) and the Université de Sherbrooke (VP). JAB developed her clinical experience in a program targeting interventions for children and teenagers using a psychodynamic approach. Her experience with children with cancer has grown through volunteer activities with the Division of Hematology-Oncology at the CHU Sainte-Justine and other organizations in this field. SS developed an expertise in pediatric psycho-oncology as a research unit director in the same hospital, originally developing research within a cognitive-behavioral orientation, he has been recently supervising qualitative research projects using Interpretative 
Phenomenological Analysis and Inductive Thematic Analysis on grief. VP is a professor of psychology and a specialist of behavioral and cognitive disorders in children. She brought a structured lay vision to interpretations. Other authors have been major figures of the development of pediatric palliative care in French-language countries. NH is a clinician and director of the palliative care unit at the same hospital, and MD is hematologist-oncologist with a long experience in clinical ethics (research and practice). ML has been a post-doc working on the initial development of the research protocol submitted to the ethics committee, after her doctorate in pediatric psychology. She is currently supervising a replication of the present study at the Université Catholique de Louvain (Belgium). Overall, our team was guided by an evidence-based approach. As a consequence, the literature and the components of existing instruments guided our preconceptions that participants would mainly focus on the absence of pain and of symptoms to describe QoL (e.g., Lyons et al., 2009; Tomilinson, et al., 2011; Varni et al., 1999). We also anticipated that QoL would be described according to a short temporal perspective (i.e. weeks or days instead of months), in line with the usual clinical observation that a child's condition can change frequently and rapidly over time in palliative care (Coombes et al., 2016; Hinds et al. 2004).

\section{Participants}

Eligible participants had to: be a member of the Department of Hematology-Oncology of our hospital, have cared for at least one child ( $\leq 18$ yrs) with advanced cancer and treated in palliative care, and speak French. Twenty health professionals were interviewed: 3 hematologistoncologists, 1 psychiatrist, 5 members of the nursing staff, 2 clinical fellows, 1 nutritionist, 1 art therapist, 1 psychologist, 3 occupational therapists, and 3 physiotherapists. Participants were 17 women and 3 men, with a mean age of $41 \pm 9$ yrs. They had been active in the hematologyoncology department for $9 \pm 7$ yrs. No exclusion criteria were used. 


\section{Recruitment}

We used the maximum variation sampling recruitment strategy (Patton, 1990). Data were collected from caregivers with various professions to ensure the representativeness of different professions in hematology-oncology and data completeness. Potential participants were selected from a comprehensive list of the members of the department $(\mathrm{N}=103)$. Each week, three professionals were randomly selected among three different professions. This random selection was chosen to favor the inclusion of different professions and avoid bias of a priori selection. Eligibility was confirmed during the first contact by email or through subsequent reminders. The caregivers who provided their consent were interviewed individually. Because the representations of QoL could differ from one profession to another, and because we wanted to make comparisons between them in a future analysis, we decided to include a number of participants higher than normally expected in qualitative research (Patton, 1990). A total of 28 caregivers were contacted, 5 did not meet the inclusion criteria and 3 refused to participate (participation rate: 20/23 87\%). We stopped recruitment when saturation was achieved in a sample including sufficient variety of professions in three categories: physicians, nurses, professionals. Notably, one factor in favor of saturation was that all participants were from one same site. The study received ethical approval from the CHU Sainte-Justine and the University of Sherbrooke. The first author (JAB) conducted the recruitment and the interviews with participants.

\section{Data collection}

Data were collected through individual semi-structured interviews (duration $1 \mathrm{hr}$ ) in which participants were asked open-ended questions according to an interview guide developed by the research team (Appendix A). The questions were adapted from Hinds et al. (2004). 
The interview process and understanding of the questions from the interview outline were approved after pilot interviews were conducted with two caregivers not included in the final sample. During the interviews, the researcher adopted an open and empathetic attitude, trying to distance herself from prior knowledge regarding QoL and to take a step back from possible interpretive categories (Paillé \& Mucchielli, 2012). At the end of the interview, participants completed a brief sociodemographic questionnaire. The interviews were recorded and transcribed for data processing.

\section{Data analysis}

The QDA Miner 4.0 software was used for coding, and the analysis was then structured on Word to allow greater flexibility of the analytical process. Data were analyzed inductively according to the thematic analysis approach (Braun \& Clarke, 2006; Paillé \& Mucchielli, 2012). Firstly, the principal investigator became acquainted with the data by transcribing and rereading the interviews. Then, according to a continual thematization process, the meaning of the text to be analyzed was extracted from each transcription by identifying codes in the margin (coding). The inventory of these codes was systematically created in a separate document (list of codes). From this list, we created the thematization journal, in which a systematic process of code identification, consolidation, integration, subdivision, and hierarchization was performed as the data was collected. During the analysis, the themes were refined, clarified, and specified by rereading the interviews, through discussions and exchanges among the researchers, and by resorting to an external expert specialized in this approach. The themes were then hierarchized in the form of central themes in order to gradually build a synthetic and structured representation of the analyzed context (thematic tree). Finally, we proceeded to the nomination and definition of these themes to describe the representation of QoL (Paillé \& Mucchielli, 2012). 
To ensure the rigor of the analysis we used recommended methodological strategies (Mays \& Pope, 2000; Whittemore et al., 2001). To ensure the reliability of our study, we used a reflexive journal to record all steps and decisions made during the analysis. The coding of transcripts was performed by the first author $(\mathrm{JAB})$ and checked by her supervisors $(\mathrm{SS}, \mathrm{VP})$. In case of divergence, consensus was sought. To ensure a sound application of the method, we called for an external qualitative analysis expert (MC see acknowledgments). On two occasions, she checked our compliance to the rules of the analysis and provided corrective advice. To ensure the credibility criteria, triangulation was used by collecting the perspective of participants from various professions. We also validated the methodological approach by way of a feed-back discussion on preliminary findings to the hematology-oncology department and at PPC/psychooncology congresses. Throughout the analysis, we discussed and exchanged on coding of transcripts and thematization within the research. In this process, as recommended by authors of the descriptive inductive analysis (Braun \& Clarke, 2006; Lapierre, 1997), specific attention was paid at all steps to the convergence and divergence of theme during their progressive definition.

\section{Results}

Following the analysis, seven domains were identified to describe the caregivers' perception of QoL in PPC in oncology: (1) Physical comfort; (2) Alleviation of psychological suffering; (3) Fun and the present moment; (4) Sense of control; (5) Feeling valued and appreciated; (6) Feeling that life goes on; (7) Meaningful social relationships. The final thematic tree is available in Figure 1.

\section{Physical comfort.}


All participants mentioned this domain as an important aspect of QoL. Mainly described by the absence of pain or symptoms or by the relief of both, physical comfort is also characterized by the satisfaction of physical needs like getting enough sleep, breathing properly, or eating without choking. Comfort is a necessary aspect of QoL, but is not considered as sufficient by caregivers.

\section{Alleviation of psychological suffering.}

QoL is also characterized by a state of alleviation in which the cognitive symptoms (e.g., hallucinations, loss of consciousness) and psychological symptoms (e.g., anxiety, psychological distress) associated with the medical condition or perceived limitations are adequately controlled.

\section{Fun and the present moment.}

This theme highlights the increasing importance of fun and the present moment in the QoL of children with advanced cancer. Professionals speak of "being in life" to describe how important it is for the child to experience fun times in which he or she is not anticipating the end of life, but is rather able to enjoy the present moment.

P4: "[...] for now, I think his quality of life is high, it's good precisely because they are very much in life, having fun and enjoying it."

Fun would be reflected in daily life through activities the child likes to do or through the presence of small instantaneous pleasures.

P7: "[...] I have a little guy in mind, well, maybe it's playing with his trucks [...] to be read a story by mom on her lap. Maybe it's simply to make soap bubbles. Maybe it's to be able to dress up as a princess. What does a child like to do? To play, to laugh $[. .$.$] it can be very small joys, as small as going outside in a stroller, it can be$ as small as to just be sitting in bed and having friends over, it can be as small as just having a hand stroked." 
Food also plays a crucial role from the caregivers' perspective. Despite the fact that the disease and treatment often affect nutrition (dietary restrictions, chewing difficulties, stomach problems.), some professionals have witnessed moments where the pleasure of eating appeared to be prominent in the child they were caring for.

P8: "I saw several children at the end of their lives for whom their pleasure was to eat. [...] There are children, I swear to you, who love to eat and whose dream is really to have a big meal prepared by their mother and to eat that during the last weeks of..."

\section{Sense of control.}

According to the professionals, a part of the QoL is linked to the feeling children have of controlling aspects of their daily life and their environment. Many caregivers reported that being in control of a situation, like being able to partake in their own care, is a crucial aspect of their QoL.

P3: "[...] we took the opportunity, when he was better, to have him partake as much as possible in his diaper change [...] keeping him active as much as possible in his activities of daily life too."

Similarly, the loss of physical autonomy is pervasive, especially in older children and teenagers. Young individuals often find themselves confronted with functional losses resulting in amputations, paralysis or a lack of energy that prevent them from performing tasks without assistance. The professionals reported that the QoL of these young individuals is characterized by their ability to do things on their own so they can maintain as much physical autonomy as possible.

P7: "[...] it's the fact of going on his own. So, for him, he would go with someone, but it wasn't, he wasn't required to go with daddy, mommy or things like... So, he would go with all his independence and he was the one to make the decisions, and so on. He had brought his money, and he paid for his meal. That had been really, really interesting." 
These young individuals are also dependent on the care provided by their relatives, which undoubtedly affects their intimacy and freedom. It is therefore essential for their QoL for them to be able to experience moments of independence by having the freedom to make decisions and to do what they want to do.

\section{Feeling valued and appreciated.}

The QoL was here associated with the feeling of appreciation the child can experience and the feeling that he or she is being valued and considered as a person, beyond his or her deficits and difficulties linked to the disease. The fact of being listened to and respected in his or her needs and desires is also a central aspect of this theme.

P7: " the quality of life, it would be to be appreciated for who he was. To say his name and to not see him for all that he was missing, but for who he was. I would say that was his quality of life $[\ldots] "$

\section{Feeling that life goes on.}

This theme refers to the maintenance of daily activities "like before the disease", and to the aspiration to accomplish or achieve dreams despite the limitations caused by the disease such as fatigue and pain. The professionals described a sense of normalcy by stressing the importance children attribute to maintaining activities they used to do before the disease or that children of the same age do.

P16: "I think that at some point too, not being at home anymore, she had been to the movies, well with the wheelchair and everything, with a friend or a couple of her friends and mom was probably there. [...] To have an activity like kids her age [...] I think all of that was like: "Wow, I was able to go see this movie, even though I was in a wheelchair!" And you know like eating popcorn. [...] Anyway, I 
remember that she was very very happy. But I think it's the fact of doing things of her age and to see the movie of the year, of that summer."

Self-actualization and the fulfillment of personal projects also is an important aspect of the QoL of young persons in PPC: pursuing secondary education, doing handiwork, being able to sit up in bed.

P6: "... the best days were the days when he was able to say that he had achieved something. It was much less than what he was able to achieve before, it could be an outing, I'm thinking of the time he went to go see the Canadians [Montreal's hockey team], it can be simpler things than what he would do before, but to have achieved something."

Thus, vitality is an essential aspect of QoL. Although the nature of the achievement can vary from child to child, it is the inner feeling gained that is important for QoL. Finally, these children still need to dream about projects that stimulate them. Thus, the possibility to daydream, to live out a childhood dream, and to have desires also characterizes their QoL.

\section{Meaningful social relationships.}

P12: "[...] in quality of life, there is also the family environment. There are children who are lucky to have amazing support from their family and very attentive parents $[\ldots]$ siblings who are very involved and who play an important role."

Maintaining meaningful relationships with those around him or her is also considered essential to QoL. When caregivers are asked to say what they think was the most important for the child they were caring for in PPC, the majority states that it seemed to be the fact of being surrounded by his or her loved ones: parents, families, friends, but also the caregiving staff. 


\section{Discussion}

This study found a descriptive model of QoL in the context of PPC, based on the views and experience of professional caregivers from a hematology-oncology department. This model distinguishes itself as previous studies have primarily focused on the perspective of children and

parents (Barrera et al., 2005; von Lützau et al., 2012; Friedrichsdorf et al., 2015; Hechler et al, 2006).

The first three themes Physical comfort, Alleviation of psychological suffering and Meaningful social relationships are consistent with the physical, emotional and social dimensions usually used to conceptualize QoL and are present in all QoL assessment tools usable in pediatric oncology (Coombes et al., 2016; Pépin, Carret, \& Sultan, 2015). The fact that the caregivers recalled these dimensions highlights that in the palliative phase of cancer, as at other times of the trajectory, the central aspects of QoL are the alleviation of disabling symptoms and pain, treating emotional distress, anxiety, and sadness, and maintaining meaningful social relationships who contribute to the sense of affiliation and need for love and security of the child.

In addition to social ties with family and friends, the results also insist on the importance of fostering meaningful relationships with professionals. Particular attention was paid by participants to the impact of interpersonal communication on the child's QoL. The role of communication between children and their parents was previously described (Barrera et al., 2005). Here, the role of communication with professionals and within the professional team was particularly underlined. Inconsistencies among team members was notably cited by them as a factor that negatively affects QoL. 
Besides, caregivers reported four other themes which were rarely mentioned or unlisted in the literature of QoL in PPC as perceived by children and their parents, but that emerged among professional participants. These themes are Fun and the present moment, Sense of control, Feeling valued and appreciated, and Feeling that life goes on. These themes are positively formulated and based on positively worded transcripts. This differs from the usual portrayal of QoL from previous studies in which the indicators are generally related to the deterioration of health, limitations, or deficits (Knapp et al., 2012; Tomilison et al., 2011).

Firstly, the Fun and the present moment theme focuses on the presence of short pleasurable moments and the ability to live the present moment. In addition to confirming the relevance of focusing on the child's degree of pleasure or on enjoyable family activities as previous studies have demonstrated (Barrera et al., 2005; Friedrichsdorf et al., 2015), the caregivers' discourse explains that the child's QoL depends on his or her ability to remain rooted in the present moment. This input also emphasizes the need to be sensitive to the child's sense of satisfaction with regard to his or her expectations and desires. It is interesting to note that the caregivers' examples were always specific and focused on a short temporal perspective. The professionals speak of "moments" and "days" - the envisioned perspective is never that of the month, as it is in the tools adapted to other contexts (e.g. PedsQL). The theme Sense of control attests the caregivers' concern regarding the pervasive influence that the loss of autonomy and sense of freedom has in the child's QoL in PPC. Although autonomy is a central aspect in many QoL models, what is new here are the very concrete examples and suggestions given by professionals to foster and maintain autonomy in children. It suggests that professional teams can do a lot on this topic. This is all the more important since caregivers have also insisted that the perception of control also serves to offset the deterioration of health. It is beneficial for their QoL 
to favor this sense of control by partaking in decisions or in care. This theme pertains to the child's life potential in relation to his or her current abilities, and again contrasts with the tendency to evaluate the child's QoL on the basis of deficits (Knapp et al., 2012).

The third new theme Feeling valued and appreciated, is rarely mentioned as a component of QoL in the literature. It mainly echoes the appreciation of the individuality and subjectivity of the child's experience with respect to his or her QoL. The professionals mostly referred to concrete actions that should be taken to favor the child's QoL. Beyond the few examples given, it is possible that this theme is particularly influenced by the norms of patient-centered care that are largely discussed in oncology. The recommendations are to provide respectful care that meets the patient's personal preferences, needs, and values, and to ensure that the patient's values guide clinical decisions (IOM, 2001). Finally, regarding the theme Feeling that life goes on, our results suggest that it is particularly important for the child to continue to engage in activities he/she did before, despite the symptoms and losses associated with the disease. This is consistent with multiple studies showing that fatigue is one of the most common symptoms and one of the most poorly supported for children throughout the cancer trajectory, particularly when it is long-lasting (Barsevick et al., 2013). Having the opportunity to engage in activities allows them to feel alive. The maintenance of activities is also related to a quest for normalcy vis-à-vis the child's peers, but also vis-à-vis himself. This theme is in line with transcripts obtained from children and parents on maintaining normalcy (Barrera et al., 2005; Kamper et al., 2010). The members of the medical team insist on the importance the sense of accomplishment and achievement of dreams has in a child's QoL. Having the opportunity to experience small accomplishments or to live out a dream certainly provides hope and strength during this time of hardship, a component that was 
identified as associated with QoL in previous research (Barrera et al,. 2005; Cataudella et al., 2014; Morley et al., 2014).

One of the reasons explaining the differences between the themes identified in our study and those from previous studies (e.g., Barrera et al., 2005; Cataudella et al., 2014) is that we collected the caregivers' perspective. It is possible that the professional position affords some degree of separation or perspective that could make it possible for certain themes to emerge more clearly. While children are often in a difficult position to articulate their QoL, the caregivers may be in a powerful position to put words to the experience of the child. Of course, this implies a high degree of responsibility as such perceptions may be biased by their own impressions or misunderstandings. Another reason is that, in contrast to the establishment of the PAC-QoL dimensions which relied on a review literature and expert panel discussions (Cataudella et al., 2014; Morley et al., 2014), our dimensions were determined inductively by participants themselves. In the research process, we attempted to disregard prior assumptions. Thus, the description offered of QoL here is based on the caregivers' experience rather than on a priori defined domains.

An important notion that emerges from this study is the specific and individual nature of the child's QoL. Most professionals were conscious of the limitations of their position. They insisted on the fact that the professional caregiver is only one of several informants on the child's status, but that the best informant would probably be the child him- or herself. These results are also in line with the utmost precision of the clinical context, as various authors have showed that the trajectory, the stage of disease development, as well as the type of cancer, should be regarded in detail in the assessment of QoL (Tomilinson, 2011; Varni et al., 2007). 
A final important idea emerging from the results concerns the limited time window to be considered when one conceptualizes QoL in this context. This has several benefits such as focusing on daily activities or achievements, and therefore providing more opportunity for the expression of positive life events instead of limitations or losses. Moreover, children who received PPC often have frequently changing symptoms which can affect their QoL and consequently a reduced time perspective makes it possible to evaluate individual changes (Coombes et al., 2016). In other words, focusing on short periods of time also increases the evaluator's sensibility regarding the variability of the QoL over time. In pediatrics particularly, children and adolescents are known to use different markers to elaborate the concept of time, and such markers change along their development (Michel et al., 2012; Rebok et al., 2001). This probably makes longer time perspectives more valid in older children. Shorter recall periods (i.e. 2 days) have already been used with success in some pediatric disease-specific measures (e.g. MSAS, Collins et al., 2002).

The limitations of this study first concern the sample. 1) Even if the themes concern the child's QoL, these themes were not identified by interviewing children and their families and therefore cannot represent the child's point of view. However, the professionals' perspective is particularly important in cases where a multi-informant strategy is used. Updating the professionals' representation of the QoL of children they care for in PPC may foster communication and more consistency within the care team. 2) Although we tried to meet caregivers from different professions, the sample allocation was not representative of staff in oncology. It is possible that this introduced biases in the frequency of certain codes, but it is unlikely to be reflected in the thematic categories as categories were not determined on the basis of frequency. Finally, the interview guide (Hinds et al., 2006) encouraged a more reduced 
temporal perspective through questions about good/bad days. However, it should be noted that a high proportion of professionals spontaneously described QoL according to a reduced temporal perspective associated with the present moment, which is even shorter than that proposed by the interview question focusing on "a good day".

Despite these limitations, this research could have important extensions. In practice, professionals could share and exchange primarily on the identified themes and delineate avenues for improvement on QoL using this framework. In research, one could present the findings to children and parents in PPC and get their impressions by using -for example- a participatory action research model. This could test the robustness of the present findings, and open on the development of a practical evaluation strategy of the validated themes. The identified components of QoL could lead to a better assessment of QoL according to the child's trajectory with advanced cancer by, for example, creating a rating scale. Recent research insists on the lack of outcome measurement in PPC (Coombes et al., 2016). Exchanging details on these components would help identify targets of individual progress: involving the child in aspects of care, improving comfort through the child's position in bed, offering the child to draw on a tablet, etc.

In conclusion, this study offers a model of how professionals having cared for children with advanced cancer in PPC conceive of QoL. Based on a descriptive inductive analysis of interview transcripts, we found three themes already present in the literature: Physical comfort; Alleviation of psychological suffering; Meaningful social relationships. Professionals also mentioned four new themes: Fun and the present moment; Sense of control; Feeling valued and appreciated; Feeling that life goes on. Future studies should explore these dimensions in children 
and their families which could help develop practical assessment tools to measure QoL in the context of PPC.

\section{Disclosures}

The authors have no conflict of interest to disclose.

\section{Acknowledgments}

The authors are grateful to the Coast-to-Coast Foundation (Canada) for financially supporting this study. Additional funding came from the Sainte-Justine UHC Foundation to the Center of Psycho-Oncology (Dr. Sultan, Montréal, Canada). We thank Dr. Mélanie Couture (Centre de recherche et d'expertise en gérontologie sociale (CREGÉS) for sharing her expertise on qualitative data management, Gabrielle Ciquier who translated the manuscript into English, and Léonor Fasse who provided comments on an earlier draft. We are indebted to the members of the Hematology/Oncology department who kindly accepted to share their experience and views. 


\section{References}

Andersen, E. M., Seecharan, G. A., \& Toce, S. S. (2004). Provider perceptions of child deaths. Archives of Pediatrics and Adolescent Medicine, 158 (5), 430-435.

Association canadienne de soins palliatifs. (2006). Soins palliatifs pédiatriques :

Principes directeurs et normes de pratique. Retrieved:

http://acsp.net/media/34584/Normes_pediatriques-

soins_palliatifs_31_mars_2006.pdf

Barsevick, A. M., Irwin, M. R., Hinds, P., et al., (2013). Recommendation for HighPriority Research I Cancer-Related Fatigue in Children and Adults. Journal of the National Cancer Institute, 105(19), 1432-1440. Doi: 10.1093/jnci/djt242

Barrera, M., D'Agostino, N., Gammon, J., et al. (2005). Health-related quality of life and enrollment in Phase 1 trials in children with incurable cancer. Palliative and Supportive Care, 3, 191-196. Doi: 10.1017/S1478951505050315

Braun, V., \& Clarke, V. (2006). Using thematic analysis in psychology. Qualitative Research in Psychology, 3(2), 77- 101. Doi: 10.1191/1478088706qp063oa

Bruera, E., Kuehn, N., Miller, M. J., et al. (1991). The Edmonton Symptom Assessment System (ESAS): A Simple Method for the Assessment of Palliative Care Patients. Journal of Palliative Care, 7(2), 6-9.

Cataudella, D., Morley, T. E., Nesin, A., et al. (2014). Development of a Quality of Life instrument for Children With Advanced Cancer: the Pediatric Advanced Care 
Quality of Life Scale (PAC-QoL). Pediatric Blood \& Cancer, 61(10), 1840-1845.

Doi: 10,1002/pbc. 25115

Comité consultatif de la société canadienne du cancer (2015). Statistiques canadienne sur le cancer 2015. Retrieved:

http://www.cancer.ca/ /media/cancer.ca/CW/cancer\%20information/cancer\%20101/

Canadian\%20cancer\%20statistics/Canadian-Cancer-Statistics-2015-FR.pdf?la=fr-

$\underline{\mathrm{CA}}$

Collins, J., Devine, T., Dick, G., et al. (2002). The measurement of symptoms in young children with cancer : the validation of the Memorial Symptom Assessment Scale in children aged 7-12. Journal Pain Symptom Management, 23(1), 10-16.

Coombes, L. H., Wiseman, T., Lucas, G., et al. (2016). Health-related quality-of-life outcome measures in paediatric palliative care : A systematic review of psychometric properties and feasibility of use. Palliative Medicine, 1-15. Doi: $10.1177 / 0269216316649155$

Friedrichsdorf, A. J., Postier, A., Dreyfus, J., et al. (2015). Improved Quality of Life at the End of Life Related to Home-Based Palliative Care in Children with Cancer. Journal of Palliative Medicine, 18(2), 143-150. Doi: 10.1089/jpm.2014.0285

Gouvernement du Québec. (2006). Normes en matière de soins palliatifs pédiatriques: Groupe de travail sur les normes en matière de soins palliatifs pédiatriques. Repéré à: http://publications.msss.gouv.qc.ca/acrobat/f/documentation/2006/06-902-05.pdf 
Hechler, T., Blankenburg, M., Friedrichsdorf, S. J., et al. (2006). Parents' perspective on symptoms, quality of life, characteristics of death and end-of-life decisions for children dying from cancer. Klinische Padiatrie, 220(3), 166-174.

Hinds, P. S., Gattuso, J. S., Fletcher, A., et al. (2004). Quality of life as conveyed by pediatric patients with cancer. Quality of Life Research, 13(40), 761-772

Hinds, P. S., Burghen, E. A., Haase, J., et al. (2006). Advances in defining, Conceptualizing, and Measuring Quality of Life in Pediatric Patients With Cancer. Oncology Nursing Forum, 33(1), 23-29. Doi: 10.1188/06.ONF.S1.23-29

Huang, I., Shenkman, E. A., Madden, V. L., et al. (2010). Measuring quality of life in pediatric palliative care: Challenges and potential solutions. Palliative Medicine, 24(2), 175-182. Doi: 10.1177/0269216309352418

Institute of Medicine (2001). Crossing the Quality Chasm: A New Health System for the 21st Century. Retrieved : http://www.nationalacademies.org/hmd/ /media/Files/Report\%20Files/2001/Crossin g-the-Quality-Chasm/Quality\%20Chasm\%202001\%20\%20report\%20brief.pdf

Kamper, R., Van Cleve, L., \& Savedra, M. (2010). Children with Advanced Cancer: Responses to a Spiritual Quality of Life Interview. Journal of Pediatric Nursing, 15(4), 301-306. Doi: 10.1111/j.1744-6155.2010.00253.x.

Knapp, C., Madden, V., Revicki, D., et al. (2012). Health Status and Health-Related Quality of Life in a pediatric Palliative Care Program. Journal of Palliative Medicine, 15(7), 790-797. Doi: 10.1089/jpm.2011.0504 
Lapierre A. (1997). La théorisation ancrée (grounded theory) : démarche analytique et comparaison avec d'autres approches apparentées. In La recherche qualitative : Enjeux épistémologiques et méthodologiques, Poupart, J. (Ed.), pp.309-340. Montréal: Gaëtan Morin Éditeur.

Liben, S., Papadatou, D., \& Wolfe, J. (2008). Pediatric palliative care: challenges and emerging ideas. Lancet, 371, 852-864.

Lyons, K. D., Bakitas, M., Hegel, M. T., et al. (2009). Reliability and Validity of the Functional Assessment of Chronic Illness Therapy-Palliative Care (FACIT-Pal) Scale. Journal of Pain \& Symptom Management, 37(1), 23-32. Doi: 10.1016/j.jpainsymman.2007.12.015.

Michel, F., Harb, F., \& Loayza Hidalgo, M. P. (2012). The concept of time in the perception of children and adolescents. Trends in Psychiatry an Psychotherapy, 34(1), 38-41.

Morley, T. E., Cataudella, D., Fernandez, C. V., et al. (2014). Development of the pediatric advanced care quality of life scale (PAC-QoL): Evaluating comprehension of items and response options. Pediatric Blood \& Cancer, 61(10), 1835-1839. Doi: $10.1002 / \mathrm{pbc} .25111$

Paillé, P., \& Mucchielli, A. (2012). L'analyse qualitative en sciences humaines et sociales. Paris: Armand Collin.

Patton, M. Q. (2002). Qualitative research and evaluation methods ( $3^{e}$ éd). Thousand Oaks, CA: SAGE Publishers. 
Pires, A. P. (1997). Échantillonnage et recherche qualitative: essai théorique et méthodologique. In La recherche qualitative : Enjeux épistémologiques et méthodologiques, Poupart, J. (Ed.), pp.113-169. Montréal: Gaëtan Morin Éditeur.

Pépin, A.J., Carret, A.S., \& Sultan, S. (2015). Quality of Life. In Pediatric NeuroOncology, Schneinemann \& Bouffet (Eds.), pp.277-288. New York: Springer Science.

Rebok, G., Riley, A., Forrest, C., et al. (2001). Elementary school-aged children's reports of their health: A cognitive interviewing study. Quality of Life Research, 10, 59-70. Doi: 10.1023/A:1016693417166

Tomilinson, D., Hinds, P. S., Bartels, U., et al. (2011). Parent reports of Quality of Life for pediatric patients with cancer with no realistic chance of cure. Journal of Clinical Oncology, 29(6), 639-345. Doi: 10.1200/JCO.2010.31.4047

Varni, J., Seid, M., \& Rode, C. (1999). The PedsQL: Measurement model for the pediatric quality of life. Medicine Care, 37, 126-139. Doi: 10.1097/00005650199902000-00003

Varni, J., Limbers, C., \& Burwinkle, T. (2007). Impaired health-related quality of life in children and adolescent with chronic conditions: a comparative analysis of 10 disease clusters and 33 disease categories/severities utilizing the PedsQL 4.0 Generic Core Scales. Health and Quality of Life Outcomes, 5(43),1-15. Doi: 10.1186/1477$7525-5-43$ 
Von Lützau, P., Otto, M., Hecher, T., et al. (2012). Children Dying from Cancer: Parents' perspectives on symptoms, quality of life, characteristics of death, and end-of-life decisions. Journal of Palliative Care, 28(4), 274-281.

Whittemore, R., K. Chase, S., \& Mandel, C. L. (2001). Validity in Qualitative Research. Qualitative Health Research, 11(4), 522-537.

World Health Organization. (2013). WHO Definition of palliative care for children. Retrieved: http://www.who.int/cancer/palliative/definition/en/ 


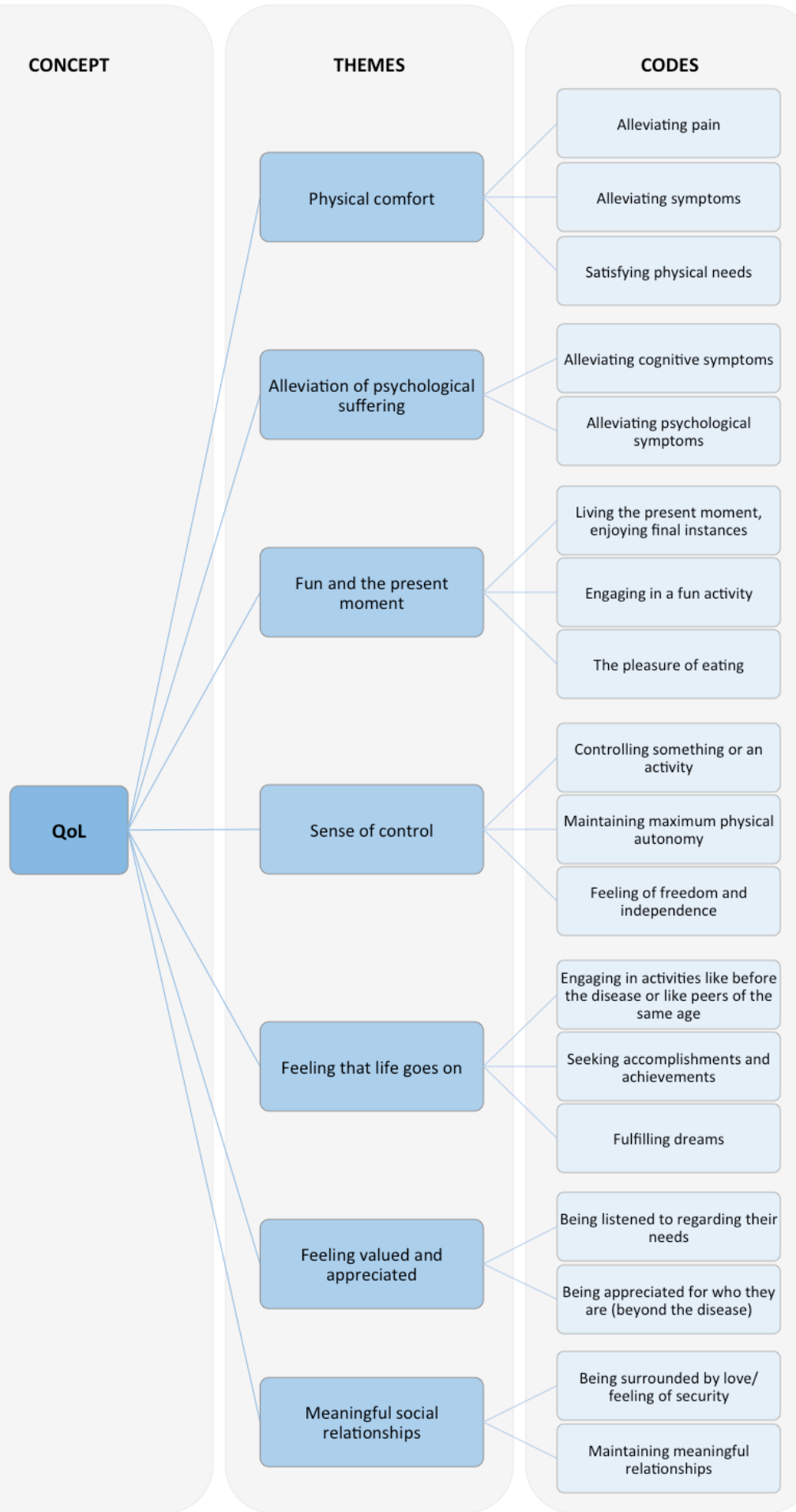

Figure 1 Quality of Life definition and domains as reflected by professionals' views in pediatric oncology 


\section{Supplementary material: Semi-structured interview guide}

1. Exploring the professional's experience in hematology-oncology with children in palliative care.

Question

- Have you encountered children suffering from cancer and receiving palliative care? If you had to quantify your experience, how many such children have you encountered in the last 12 months?

- Can you recall one of these children specifically?

- What types of services did you provide him or her with? For how long? How often?

- Could you briefly describe the type of relationship you had, as a caregiver, with this child that you knew in palliative care?

\section{Identifying the professional's perceptions of the child's QoL.}

Purpose: Indirectly itemize the components of QoL as perceived by the caregiver. Questions

Still recalling this child.

- According to you, what was it that made this child have a good day? A bad day? A good time? A bad time? Do you remember one of those moments? (Identify and explore the elements adduced by the participant to meet his/her perception of the components influencing the child's good/bad day and good/bad time.)

- In your opinion, what was most important for this child in palliative care?

- Now, if we think more generally, what do you think defines a good day for a child with advanced cancer in palliative care? And what defines a bad day?

3. Identifying the professional's perceptions of the child's QoL and activities or trends involved in defining a good or bad QoL for the child 
Purpose: Itemize, with more concrete questions, the components of QoL as well as those influencing the child's QoL as perceived by the caregiver.

\section{Questions}

- Could you describe the QoL of the child for whom you provided care to?

- If we think more generally about children with cancer in palliative care, what would be the criteria to consider in the evaluation of their QoL?

- Finally, what would be your definition of QoL in pediatric palliative care?

Is there anything else you would like to add concerning the QoL of children with advanced cancer in palliative care? 